\title{
Transitions to motherhood: young women's desire for respectability, responsibility and moral worth
}

\section{Dr Kay Calver}

\begin{abstract}
In the UK, teenage motherhood is depicted in the media and government policy as highly negative and problematic. Pregnant and mothering young women are constructed as socially excluded members of society who belong to an assumed underclass who lack responsibility and respectability. This article draws on the views and perspectives of pregnant and mothering young women in the east of England to examine how positive and successful subjects are defined and understood. It is illustrated how this group of working class young women negotiated and resisted their positioning as 'unfit' mothers and 'bad' citizens. Central to their narratives was a desire to reassert themselves as respectable and responsible individuals through engaging in education and employment in order to achieve financial independence. It is argued that this notion of respectability provides a limited and limiting understanding of inclusion and moral worth for working class young women.
\end{abstract}

Key words: transition, identity, parenthood, exclusion, employment

\section{Introduction: teenage pregnancy - narratives of lack}

Ellis-Sloan (2018) argues that in the twenty-first century the surveillance of working class women and the choices they make regarding education, employment and family has intensified. Young (1999, vii) explains that 'at no other time have so many people gazed at so many others and has every normative nuance been so measuredly scrutinized'. This growing contemporary emphasis on the freely choosing individual asserts that individuals are capable of freely forming and changing their lives. This has led to moral judgments about young 
women's lives and how pregnant and mothering young women can find themselves defined from the outside, positioned, placed and judged in relation to dominant expectations and norms. Vincent and Thomson $(2013,7)$ explain 'in not conforming to current norms about the appropriate age to begin childbearing, they have become moral scapegoats who are seen as having the "wrong" values, the 'wrong" aspirations and making "wrong" choices'. This article therefore explores the ways in which normative expectations influence young women's desire for change and what they considered possible, appropriate and positive.

Teenage pregnancy is conceptualised as inherently problematic and a cause of social exclusion in the media and government policy (Rudoe 2014). Being a young mother is commonly associated with negative outcomes for both mother and child. It is asserted young mothers are at an increased risk of poverty, low educational attainment, lower rates of economic activity and a dependency on state benefits (Aspinall and Hashem 2010). Teenage pregnancy is therefore associated with a raft of risks, problems and negative orientations and is linked with intergenerational poverty and disadvantage. There is a strong emphasis placed on the perceived decline in morality and family life, with concerns surrounding working class mothers and their capability to raise their children to be law abiding and productive citizens (Gillies 2007). Young mothers' lack of engagement in education and employment is commonly at the centre of discussions surrounding teenage pregnancy. These young women are seen as having rejected educational opportunities and hence are defined as an 'at risk' group and as excluded members of society (Vincent 2012).

Skeggs and Loveday $(2012,473)$ argue that working class mothers are believed to be 'bearers of bad culture, faulty psychology, [and] as potentially dangerous, degenerate and underserving' members of society. This moral underclass discourse can be seen to refer to 
cultural rather than material explanations of poverty and disadvantage. It emphasises a moral crisis in which young mothers can be blamed for the poverty and disadvantage they experience as they are seen to exhibit inappropriate behaviours and actions and do not appropriately capitalise on the opportunities made available to them (Levitas 1998). Due to a highly individualistic focus and explanation of the 'problem' of teenage pregnancy, Gillies (2005) argues young women are not seen as victims, but as failures in self-governance, unable or unwilling to appropriately capitalise on their lives. This highlights how the underclass discourse acts to draw moral distinctions between the respectable and the abject. Skeggs (2011) asserts working class young mothers are therefore regarded as 'value-less' subjects who represent the source of the social problems experienced by society. Pregnant and mothering young women are therefore positioned to be 'risky' young people who are increasingly targeted for responsibilisation and remoralisation.

\section{Recognition of stigma: striving for respectability}

Due to the pervasive construction of teenage motherhood as highly problematic pregnant and mothering young women are acutely aware of their positioning as undesirable and deviant individuals in society (Kamp and McSharry 2018, Bermea, Toews and Wood 2018). Skeggs (1997) argues that when women are conscious of their classifications, their devaluing within society, their inability to perform correctly and to be without shame and judgement they commonly turn to respectability and responsibility as a means of establishing a valued and legitimate way of being and way of being seen. Respectability would not be something desired by women, to prove and achieve, if it had not been seen to be the property of 'Others', those who were valued and legitimated. Sayer $(2005,950)$ explains:

we are normative beings, in the sense that we are concerned about the world and the well being of what we value in it, including ourselves. The most important questions 
people tend to face in their everyday lives are normative ones of how to act, what to do for the best, what is good or bad about what is happening, including how others are treating them.

This highlights that there is a set of shared assumptions about what is 'right', 'natural' and 'good'. These assumptions shape and influence how positive and successful lives are defined and what is classified as a life worth pursuing (Hoggart 2009). However, it is important not to simply accept the labelling of some young women as problems, but to examine and challenge these labels. Questioning what and whom is deemed problematic and by whose definition is important as concepts of appropriate and positive mothering are inevitably implicated in dominant values and beliefs. O'Neill (1996, xi) explains:

normativity pervades our lives. We do not merely have beliefs: we claim that we and others ought to hold certain beliefs. We do not merely have desires: we claim that we and others not only ought to act on some of them, but not others. We assume that what somebody believes or does may be judged as reasonable or unreasonable, right or wrong, good or bad, that it is answerable to standards of norms.

It is therefore important to critically consider what is classified as respectable mothering and how this imposes limits on the lives and experiences of pregnant and mothering young women. Working class mothers have been subject to intense scrutiny in relation to the 'choices' they make regarding education, employment and family life (Allard 2007) and have commonly been framed in social and political discourses as inadequate and unfit mothers (Gillies 2007). Consequently, working class young women struggle to assert a legitimate maternal identity (Hamilton et al. 2018). This article considers how pregnant and mothering young women negotiate the stigma associated with teenage pregnancy and how they understand and wish to represent themselves within this discourse. 


\section{The research study}

This article draws on research data from a doctoral study that explored the narratives of pregnant and mothering young women. The study was designed to explore their experiences of teenage pregnancy and motherhood and how they felt becoming pregnant had influenced their lives. The study adopted the critical stance advocated by social constructionism, alongside an interpretative phenomenological approach (IPA). One of the overarching aims of the study was to explore and challenge the 'inherited and prevailing perceptions of what it means to be a women and how women ought to live and act' (Crotty 1998, 197). To achieve this, semi-structured interviews were conducted with fourteen young women to consider how positive and meaningful lives are constructed in relation to pregnancy and motherhood. Interviews were ideally placed to help capture the complexity of the young women's lives and the relative impact and influence of key events (Smith, Flowers and Larkin 2009).

The research study was conducted in a location in the east of England. The city is characterised by both prosperity and economic deprivation, varying between the different wards. The young women involved in this study lived in deprived areas of the city that were experiencing economic decline, high unemployment levels, deteriorating housing conditions and concerns surrounding community safety and social support. The housing estates in which the young women lived were among the top twenty most deprived wards in the region.

During the study four means of recruitment were established. First, a young mums to be unit designed for young women soon to become, or having recently become, mothers. The courses offered focused on antenatal education, preparation for motherhood, recognition of the responsibilities involved in caring for children, numeracy, literacy, job search skills, information on employment and training opportunities. Young women were also approached 
to be involved in this study at a college information day specifically targeted at pregnant and mothering young women, those residing in a housing support scheme for mothers and finally through peer referral.

\section{The participants}

Fourteen young women were involved in the research study, they were aged between fifteen and eighteen years at the time of interview, with a mean age of seventeen. Seven of the participants were pregnant, and the other seven were mothers. Of those who were pregnant Holly was at the earliest stage of pregnancy at thirteen weeks, and at the other end of the scale, Fay was forty-one weeks pregnant, waiting to be induced. The majority of participants were in their third trimester of pregnancy, between twenty nine and forty weeks.

Of those who were young mothers, their children ranged in age from three months to twenty two months, with an average age of eleven months. Gemma was the youngest mother, who became pregnant just after her fifteenth birthday and Beth was the oldest mother, who conceived her child when she was eighteen. Twelve of the young women described themselves as White British and two described their ethnicity as Black British. Four of the fourteen young women were sixteen or under. Two were attending a mainstream school, and the other two were attending the young mums to be unit on a full-time basis. The other ten young women were beyond the age of sixteen of which four were attending a local college, two were attending the young mums to be unit and four were classed as not in education, employment or training (NEET). 


\section{Positionality}

I was similar to the young women involved in this study, in terms of our shared gender, comparatively young age and coming from a working class background. However, I am also aware that there are many structural and individual differences. For example, I was a $\mathrm{PhD}$ student which would suggest my own privileging of education and I had not yet experienced motherhood myself. Due to my 'non-mothering' status I was often seen by the young women as 'unknowing', which meant they did not presume I understood or had experienced what they were discussing. I found this often led to more detailed descriptions of their experiences of pregnancy, motherhood and education, in order to 'educate' me as a non-mother.

\section{Data analysis}

Interpretive phenomenological analysis (IPA) was conducted which is concerned with the close line-by-line analysis of the experiential claims, concerns and understandings of participants (Larkin, Watts and Clifton 2006). This involves the identification of emergent themes, emphasising convergence and divergence, commonality and nuance, first for individual transcripts and then across multiple transcripts (Eatough and Smith 2008). This circularity of interpretation is effective in producing a non-linear and dynamic style of thinking which typifies IPA as an iterative and inductive style that utilises a method of 'moving from the particular to the shared and from the descriptive to the interpretive' (Smith, Flowers and Larkin 2009, 79). IPA has five distinct phases which will be outlined below.

\section{Stage One: Transcription and initial coding}

The interviews were transcribed verbatim, including any short pauses, laughter, and the participants' own grammar and dialect. Once transcribed, the first stage of IPA was to read and re-read the transcript in order to become familiar with the content. The transcript was 
then subjected to close, line-by-line analysis, examining the content and use of language. The purpose of this stage was to produce a comprehensive and detailed set of notes about each transcript that reflects the researcher's initial thoughts and observations. There was a focus on descriptive comments, identifying significant objects, events, experiences and people in the participant's narrative, taking things at 'face value'.

\section{Stage Two: Developing emerging themes}

The data created through initial coding in stage one was then synthesised to identify emerging themes. Whilst the initial coding was largely descriptive, open and contingent, the emergent themes attempted to capture and reflect an overall understanding of the data. This process involved breaking up the narrative flow into distinct sections of text, in order to perform a more detailed conceptual analysis and to ascribe the text to a theme.

\section{Stage Three: Searching for connections across emergent themes}

A set of emergent themes were established for the transcript in stage two. This next stage of analysis refined the themes and considered how they fit together. Looking for a means of drawing together the emergent themes and producing a structure that allowed the identification of the most interesting, unusual and important aspects of the participant's account. The emergent themes from stage two were listed and then reorganised to form clusters of related themes. This is referred to as abstraction and is the process of identifying patterns between emergent themes (Smith, Flowers and Larkin 2009). It involves organising similar emerging themes together and developing a new name for that cluster. 


\section{Stage Four: Moving to the next case}

The next stage involved moving to the next participant's transcript and repeating stages one to three for each of the fourteen transcripts. Smith, Flowers and Larkin (2009) stress that it is important to view each transcript on its own merit, in order to allow new themes to emerge with each case.

\section{Stage Five: Looking for patterns across cases}

The next stage involved looking for patterns across the transcripts. The transcripts were assessed, looking for connections and deciding which themes were most significant. After analysing each individual transcript and reviewing the fourteen transcripts as a whole, sixteen emergent themes were identified (see Table 1).

Table 1 List of emergent themes from all transcripts

\begin{tabular}{|l|l|}
\hline Appropriate femininity & Relationships with teachers \\
Change & Respectability \\
Choice & Sense of loss \\
Exclusion & Social inclusion \\
Expert advice & Stigma \\
Good mothers & Success \\
Othering & Tainted reputations \\
\hline
\end{tabular}

For the purpose of this article, the following sections will explore the themes of change, good mothers, othering, respectability, social inclusion, stigma and notions of success in order to 
examine how the young women sought to reimagine themselves within the negative discourse of teenage pregnancy.

\section{Recognition of stigma}

The young women involved in this study were acutely aware of the stigma, shame and judgement typically associated with teenage pregnancy, for example:

I think some people, like, they don't say it, but like, oh she's pregnant, she is so young, she is never going to do anything, she's not going to get an education, she's not going to get a job.

(Danielle, 16 years old, pregnant)

Just a lot of people think that young mums can't do it and that you don't have a paying job, blah, blah, blah, but it doesn't mean anything.

(Fay, 17 years old, pregnant)

Some friends who have been like, oh I would never get pregnant and saying like, oh your life it's ruined.

(Holly, 16 years old, pregnant)

When you are a pregnant teenager everybody looks at you and thinks you know you haven't got a job and all this.

(Melissa, 17 years old, pregnant)

The young women acknowledged the construction of teenage motherhood as a uniformly negative experience for both themselves, their children and for society as a whole. Childbirth is typically positioned as a positive event, one to be celebrated, but in the case of teenage mothers it is invariably positioned as a social or public health issue (Wilson and Huntington 2005). This negative discourse of teenage pregnancy and motherhood was entwined 
throughout the young women's narratives and was frequently used as a basis to explain, justify and defend their decisions and actions. Skeggs (1997) draws attention to how working class women's lives have typically been scrutinised by people in positions of power and authority with regard to respectability and decisions about how they choose to live their lives which have been used to classify them into categories of the deserving and undeserving poor. The young women's use of language, for example, "they" and "everyone" to describe their experiences of teenage pregnancy demonstrates how they felt judged, assessed and watched by 'Others'. They felt their difference was marked by their age, their visible pregnant bodies and a public assumption that they were not engaged in activities that accrued value - that being participation in education and employment.

There is an acknowledgement of the popular construct of teenage mothers as lacking aspiration, not engaging in any meaningful participation and as irresponsible welfare dependents. However, Fay's use of "blah, blah, blah" suggests that while she commonly encountered this negative perception of teenage pregnancy and motherhood, she did not agree with this viewpoint and she implies a boredom and rejection of these dominant discourses.

The stigma associated with teenage pregnancy and motherhood illustrates how an expectation for middle class women to achieve highly in education, to establish a professional career and then perhaps start a family has become the normative and expected trajectory for all women. Women in the Western world are judged and assessed by this standard. When they do not follow this trajectory, or do so in a different order, as is the case for pregnant and mothering young women, they become targets of marginalisation and stigmatisation (Wilson and Huntington 2005). Normative and expected trajectories are therefore entwined with beliefs about how people should lead their lives and what makes a life worthwhile. 


\section{Achieving responsibility and respectability}

The main forms of respectability identified in the young women's narratives were caring and loving their children, achieving in education and employment and being able to provide financially for their family. Their narratives therefore demonstrated their attempts to avoid being stigmatised as mothers who were seen as irresponsible and unable to provide for their child. A key feature in the young women's narratives was a commitment to doing "what's right" to ensure they became a responsible and dependable mother for their child. For example, Laura explained:

I know that I have got to step up and be an adult now, whereas before I was pregnant I could act silly when I wanted to, I could do what I wanted to and no one would be bothered. But now I can't act silly, I can't go clubbing, I have got to do what's right for me and my baby and that's what I will do. So it's not going clubbing every weekend and wasting my money on McDonalds and stuff like that. My baby comes first so whatever my baby needs, my baby will have and I will get what I need after if I can.

(Laura, 18 years old, pregnant)

Pregnancy provided a rite of passage to adulthood and the impetus to become more responsible and mature, as illustrated when Laura stated: "I have got to step up and be an adult now". Becoming a young mother can help provide a strong sense of identity, belonging and purpose because they are now responsible for another person's life (Cherry et al. 2015). This can arouse feelings of maturity, responsibility, self-worth and a new focus for their lives. In contrast with stereotypical representations of teenage pregnancy, rather than a loss that jeopardised their future, the young women often described pregnancy and motherhood as a gain that contributed to their maturity. Laura's statement: "my baby comes first so whatever my baby needs, my baby will have" draws on the wider public discourse which emphasises that a child's needs are paramount and that it is a woman's primary role to look after and 
nurture their child (Graham and McDermott 2005). Being able to provide for their child, especially financially, was equated with good and respectable mothering. Laura can therefore be seen to be drawing attention to and highlighting that she is a caring and responsible mother who gives primacy to the relationship with her child.

Pregnant and mothering young women attempt to reject the teenage mother as an unfit mother identity by investing in what they perceive to be a good mother identity. Rolfe (2008) explains this commonly includes projecting a self-sufficient and autonomous image, a young woman who is mature, sensible, responsible and financially independent. In the example of Laura, her attempts to emphasise her maturity and responsibility can be interpreted as an attempt to challenge and contradict dominant representations of teenage mothers as too immature to be good mothers. Her narrative provides an alternative view of young women who are often represented as irresponsible, irrational or feckless. In comparison to the dominant discourse of teenage pregnancy, Ellison (2003) argues that deciding to continue with pregnancy can be seen to represent active agency, self-determination and responsibility.

There was a common perception that if they were not able to gain recognised qualifications and paid employment they would be perceived as unsuccessful subjects both through self and external definition. An unsuccessful future was commonly characterised by a dependency on state benefits, which was something many of the young women held in contempt, for example:

To try and get a future for me and my baby, to give him what I didn't have and to have like a job and not be like some teenage mums where they are on benefits. (Gemma, 15 years old, pregnant) 
She [her mother] is on the dole [laughs] and I don't want to end up like her [laughs].

(Holly, 16 years old, mother)

I couldn't sit on benefits, I struggle now, I couldn't imagine in ten year's time still doing it, because the benefits are getting cut less and less.

(Amber, 18 years old, mother)

There was a belief that a dependency on state benefits would position them within the stereotypical representations of teenage motherhood, which was a positioning they were seeking to escape. The young women's antagonism towards state benefits is indicative of the association between dependency on welfare and individual failure (Young 1999). Ellis-Sloan $(2018,197)$ states 'in contrast to older mothers who stay at home to care, young mothers are subject to questions with regards their dependency'. While many of the young women were claiming benefits they were adamant that their dependency on benefits was only short term until they succeeded in education and employment and became self-sufficient.

Engaging in education and employment was seen as a means to counteract the dominant negative discourses surrounding teenage motherhood, as they could demonstrate that while they had become pregnant during their teenage years, they had gone on to achieve. The young women can be seen to identify with notions of success that assert identity and belonging are secured through paid employment and that a person's relationship with the labour market determines whether they are socially included or socially excluded. Paid work itself was constructed as almost a condition of citizenship (Levitas 1998) and as the backbone of the standard biography (Beck 1992). The young women can be seen to accept this construction of positive and successful lives because they commonly perceived paid 
employment as a key indicator of success and they wished to conform to those behaviours they believed conferred success. For example:

I am going to finish off my course because I don't want to be just doing nothing, because my brother is doing something, I just want to make, but obviously my parents, my mum's really proud of me because I am having a baby and she can't be any more proud than that. But I still need, as much as I will still have a life, like my baby is going to be in my life, but I need something to show for my life. I need to still make something to show for my life, apart from a family.

(Fay, 17 years old, pregnant)

There is a suggestion that personal value and inclusion cannot be achieved solely through motherhood and that Fay needed to achieve academically and professionally in order to have something to "show" for her life. Williamson $(1997,78)$ uses the powerful yet contentious metaphor of 'Status ZerO' to refer to young people who are not in education, employment or training, as they appear to 'count for nothing and appear to be going nowhere'. Within this discourse those who 'fail' are branded, and to some degree, come to see themselves as valueless or 'nothings' (Reay and William 1999). Fay's narrative reflects this discourse because there is an insinuation that if she is 'just' a mother this would mean she would be doing "nothing" with her life. Hey and Bradford (2006, 55, original emphasis) argue:

working-class women have no choice but to position themselves in relation to respectable bourgeois femininity and discourses of improvement. Aspiring and competent mothers with careers and 'successful' children are set as the norm for how middle-class femininity defines itself, and have become the yardstick against which all mothers are to be measured.

Skeggs (2011, 503, original emphasis) explains the working class women in her study 'spent an enormous amount of time attempting to attach value to themselves to defend against 
misrecognition and devaluation, through the performance of respectability and by reversing dominant symbolic moral values'. The pressure and expectation to be successful and respectable is further reflected in Amber's narrative as she frequently made comparisons between herself and other young mothers to situate her narrative and to explain and justify her own actions, for example:

You see these mums that are like, no disrespect to them, but they have a baby at seventeen and their like, nineteen now and their child is two and they just don't do anything for themselves, they just sit there, and I'm like why would you want a life like that? I couldn't imagine, like, my daughter's not even one yet and I can't wait to go back to college and have a better social life and know that I am going to get somewhere in life.

(Amber, 18 years old, mother)

Amber demonstrated a need to maintain her visibility against which success can be affirmed by comparing and contrasting herself to what she perceived as a 'bad' mother. Through this she was able to confirm and cement her positioning as a 'good' mother who embodied the correct characteristics and attitudes towards education, participation and motherhood. 'Good' mothers in this context were seen to be proactive, independent and self-supporting, whereas 'bad' mothers were characterised as welfare dependent, lacking in meaningful activity and lazy. Amber desired to stress she did not align with stereotypical notions of teenage motherhood through demonstrating, acknowledging and emphasising her difference.

This can be seen as a process of 'Othering', which is defined by Weis $(1995,18)$ as 'that process which serves to mark and name those thought to be different from oneself". Amber can be seen to be attempting to separate and distance herself from other young mothers by describing the ways in which she is not like "these mums". Amber positioned herself and her 
values in opposition to those of other young mothers, weighing up and judging them against her own personal aspirations and beliefs in order to confirm and validate her own choices. Sayer $(2005,953)$ refers to this as moral boundary drawing which 'denotes the way in which social groups often distinguish themselves from others in terms of moral differences, claiming for themselves certain virtues which others are held to lack'. Moral boundary drawing is believed to be particularly evident in groups that are anxious about their status in society and how they are viewed and perceived by others. Due to the intense scrutiny pregnant and mothering young women experience it is perhaps unsurprising that they feel a need to highlight and emphasise their 'positive' morals, values and behaviours in comparison to "these mums" who are seen to represent stereotypical notions of teenage pregnancy.

The young women can be seen to be projecting competent identities to counter the stigma that they experience. Similar to the findings of Zito $(2018,1102)$ the young women can be seen to 'highlight the positive aspects of a status that is vilified in the broader culture, allowing them to "reauthor their lives" and rescue a spoiled identity'. Being proactive and taking responsibility for their lives through engaging in education and employment was highly valued by the young women and central to their claim to respectability. 'Other' mothers who "do nothing for themselves" and rely on state benefits were subject to strong disapproval. This suggests that to be respectable is to have made good choices and acted independently in order to achieve their goals and aspirations; to fail is to have made bad choices, not to act at all, or acted counter to what is believed to be in their own or children's best interests (Hemmings and Kabesh 2013). 


\section{Limited and limiting notions of success}

Despite the young women asserting their respectability through engagement in education and employment and being a 'good mother', Amber acknowledged that she would still be subject to disapproval from the middle class gaze, as she explained:

If you see someone come out of something, from like having a baby, that can change her life and do better in life, like get an education, I think most people would look at me and be like it's not good having a baby and you shouldn't think oh having a baby has changed my life, but then I see it in a way that because she has had a baby she is not in prison, do you know what I mean? She didn't go down that path, she changed her life and she wants to do something with herself, that's the way they have to see things, if they knew from my perspective, but obviously they are always going to judge you for it because you are a young mum at the end of the day. Anyone can be a mum, you've just, anyone can be a mum, just because you're young doesn't mean you're going to be a bad parent or you're not going to be able to cope, anyone can suffer from postnatal depression, anyone could be a bad mother, anyone can be a good mum, do you know what I mean?

(Amber, 17 years old, mother)

Phoenix (1991) explains constructions of 'young mother' and 'good mother' exist in public consciousness as mutually exclusive categories. Amber's narrative suggests the assumption that teenagers are too young to be good or capable mothers still prevails. There is an interesting shift from the first to the third person that perhaps illustrates how Amber wanted to be perceived by others. Amber acknowledged the profound impact she believed pregnancy had on her life. This is how she wanted to be understood by others, not as an irresponsible teenage mother, but as a success story and a survivor, who managed to forge a new life for her and her child. However, Amber felt she would never be deemed a capable or a good mother by others, as suggested in "obviously they are always going to judge you for it 
because you are a young mum at the end of the day". Amber was conscious of her social positioning as a young mother and how her early motherhood status would be negatively viewed and judged by others.

Amber needed her status and identity as a good and respectable mother to be acknowledged and recognised by others in order to confirm and cement her understanding of self. Speaking of the experiences of working class women involved in her study, Skeggs $(1997,4)$ explains 'she operates with a dialogic form of recognition; she recognises the recognition of others. Recognitions do not occur without value judgements and the women are constantly aware of the judgements of real or imaginary others'. Youdell (2006) asserts subjects need meaning to be attached to them in order to make them accessible and intelligible. Consequently:

the subject is understood as the person made in relations of productive power. Subjectivity, then, is taken as this subjectivated subject's particular subject position; her/his sense and experience of her/himself; as well as her/his audiences' understanding of "who" s/he is and can be (Youdell 2006, 48).

These recognitions enable young women to navigate themselves through classificatory systems and measure and evaluate themselves accordingly. Rawls (1971) argues that it is impossible for people to maintain the conviction that how they live their lives and that what they do is meaningful and worthwhile if they are not recognised and valued by dominant others. This illustrates the difficulties young women encounter in developing positive and respected identities as working class mothers.

The young women's desires to obtain recognised qualifications in order to secure paid employment and to achieve financial stability can be seen to be fraught with difficulties and 
contradictions. Walkerdine, Lucey and Melody $(2001,25)$ caution against the generalising tendency of discourses surrounding social mobility and draw attention to the 'illusion of social mobility though education' which is implicit in these discourses. Successive governments have presented obtaining paid employment as a significant factor in the alleviation of poverty. The importance of achieving recognised qualifications in order to secure paid employment is explicit in government rhetoric and the young women's own narratives. However, Devins et al. (2014) argue that entering employment does not always prove to be a sustainable route out of poverty as there are substantial issues in the twenty-first century surrounding job security, wages and career progression. Alldred and David (2010) argue that even if teenage mothers did prescribe to these middle class norms and expectations regarding engaging in motherhood alongside education and employment, it is highly optimistic that they would be able to achieve respectability and social inclusion via establishing a successful career given the limited number of job opportunities in the neighbourhoods they are likely to reside. This imposes limits on young women's respectability if the standards to which this is determined are out of their reach due to a highly volatile employment market. In addition, it assumes that paid work is the best and only way to accrue value in society and to be deemed respectable (Hey and Bradford 2006).

The young women's narratives highlight a belief that 'just' being a mother does not offer sufficient value within society. Their narratives focus on the importance of education and employment in order to ascribe value and importance to their lives. The assertion that a lack of involvement in education and employment leads to social exclusion has been criticised as it defines social inclusion in purely economic terms (Alexiadou 2002, Kidger 2004). Defining social inclusion in terms of paid employment devalues other forms of social participation that are outside formal education and employment, which includes those associated with 
motherhood itself (Kidger 2004). The belief that paid employment equals social inclusion provides a limited and simplistic understanding of inclusion and participation in society. It is a construction of inclusion that does not value or recognise the varying roles and responsibilities women occupy within society other than paid employment. This invokes key feminist dilemmas such as the conflicts between the public and private spheres, between paid work and unpaid care work and between women's reproductive rights and their rights to economic independence. Vincent and Thomson $(2013,7)$ argue:

in the developed world, 'rational economic man' assumptions prevail and both men and women are expected to be economically active. Childbearing becomes an inconvenience to be fitted around employment which is deemed to be more important. Productive labour is afforded high social status while reproductive labour is not.

The assertion that being a full time mother is not a sufficient or legitimate form of social inclusion seems to be highly ingrained in discussions surrounding teenage motherhood and social inclusion. Teenage mothers are expected to be mothers and to engage in paid employment in order to meet their obligations as citizens and to provide financially for their children (Ellis-Sloan 2018). This reflects changing definitions and expectations of participation and success for young women in the neoliberal era (Hamilton et al. 2018). The devaluing of motherhood and the unpaid carer role contributes to the positioning of pregnant and mothering young women as problematic as they are seen to be deviating from an expectation to engage with paid employment and to be self-supporting. Broader conceptualisations of social inclusion are therefore required so that young women who are not economically active, but who contribute to society through their mothering, caring and domestic work are recognised and valued. 


\section{Conclusion}

This article has demonstrated how pregnant and mothering young women are constructed as 'value-less' subjects who are depicted to be unemployed, uneducated and irresponsible in public, political and academic discourses. The young women's narratives illustrated an acute awareness of these stereotypical representations and they expressed a strong desire to distance themselves from this dominant negative discourse. The young women attempted to challenge and contradict these stereotypes by framing their narratives through their engagement with education and employment. Reimagining themselves as productive, educable subjects who have taken responsibility for bringing about change in their lives was central to their claims to respectability.

The negative and problematic construction of teenage pregnancy and motherhood reflects how middle class values and expectations relating to education, employment and when to start a family have become the normative and expected trajectory for all women. The young women involved in this study can be seen to be engaged in a process of comparison, comparing their experiences, achievements and lives in relation to the rules, standards and expectations that are defined and set by the privileged group, the middle and upper classes. The young women felt they were judged and assessed by their participation in education and employment and whether they were dependent on state welfare. In order to distance themselves from the negative stigma associated with teenage pregnancy they felt compelled to prove they were not like "these mums" who they felt encapsulated these stereotypical representations. However, some of the young women felt that no matter how hard they tried to transform their lives they would never be deemed respectable by external judgement and would always be seen to be 'lacking' in some capacity due to their age at the point of motherhood. 
Constructions of responsible and respectable motherhood were therefore significantly influenced by engagement in education and employment. The need to challenge and resist their positioning as 'unfit' mothers and 'bad' citizens meant they actively constructed themselves as projects to be worked on, to be transformed and improved. Judging respectability and moral worth based on a person's involvement with education and employment is highly problematic because it constructs social inclusion in purely economic terms. It assumes that paid work is the best and only way to achieve value in society and that it is almost a condition of citizenship. This devalues the unpaid carer role and places limits on who can claim respectability within society. In doing so it provides a limited and limiting definition of a successful and positive life.

\section{References}

Alexiadou, N. 2002. "Social inclusion and social exclusion in England: tensions in education policy", Journal of Education Policy, 17(1): 71-86.

Allard, A.C. 2007. "Assembling selves: "choice" and the classed and gendered schooling experiences of 'marginalized' young women" In Learning from the Margins: Young Women, Social Exclusion and Education, edited by J. McLeod and A.C. Allard, 143156, London: Routledge.

Alldred, P. and David, M. 2010. "What's important at the end of the day? Young mothers' values and policy presumptions" In Teenage Parenthood: What's the Problem?, edited by S. Duncan, C. Alexander and R. Edwards, 24-47, London: Tufnell Press.

Aspinall, P.J. and Hashem, F. 2010. "Are our data on teenage pregnancy across ethnic groups in England fit for the purpose of policy formulation, implementation, and monitoring?" Critical Public Health, 20(1): 47-70.

Beck. U. 1992. Risk Society: Towards a New Modernity, London: SAGE.

Bermea, A.M., Toews, M.L. and Wood. L.G. 2018. “'Students getting pregnant are not gonna go nowhere': manifestations of stigma in adolescent mothers' educational environment" Youth and Society, 50(3): 423-436.

Cherry, C., Chumbler, N., Bute, J. and Huff, A. 2015. "Building a 'better life': the transformative effects of adolescent pregnant and parenting" SAGE Open: 1-9. 
Crotty, M. 1998. The Foundations of Social Research: Meaning and Perspective in the Research Process, London: SAGE.

Devins, D., Bickerstaffe, T., Mitchell, B., and Halliday, S. 2014. Improving Progression in Low-Paid, Low-Skilled Retail, Catering and Care Jobs, York: Joseph Rowntree Foundation.

Eatough, V. and Smith, J. A. 2008. "Interpretative phenomenological analysis" In The SAGE Handbook of Qualitative Research in Psychology, edited by C, Willig and W. Stainton-Rogers, 179-194, London: SAGE.

Ellis-Sloan, K. 2018. "Personal decisions, responsible mothering: unpicking key decisions made by young mothers" In Re/Assembling the Pregnant and Parenting Teenager: Narratives from the Field(s), edited by A, Kamp and M. McSharry, 195-217, Oxford: Peter Lang.

Ellison, M.A. 2003. “Authoritative knowledge and single women's unintentional pregnancies, abortions, adoption, and single motherhood: social stigma and structural violence", Medical Anthropology Quarterly, 17(3): 322-347.

Gillies, V. 2005. "Raising the 'meritocracy': parenting and the individualization of social class", Sociology, 39(5): 835-853.

Gillies, V. 2007 Marginalised Mothers: Exploring Working-class Experiences of Parenting, London: Routledge.

Graham, H. and McDermott, E. 2005. "Qualitative research and the evidence base of policy: Insights from studies of teenage mothers in the UK", Journal of Social Policy, 35(1): 21-37.

Hamilton, P., Lawson, E., Gaudet, C., Chisholm, J., Kaur, J. and Abercromby, S. 2018. “At the intersection of idealized youth and marginalized almost-adulthood: how girls negotiate young motherhood in London, Ontario". Journal of Youth Studies, 21(9): 1182-1197.

Hemmings, C. and Kabesh, A.T. 2013. "The feminist subject of agency: recognition and affect in encounters with 'the Other'" In Gender, Agency and Coercion, edited by S. Madhok., A, Phillips., and K. Wilson, 29-46, Basingstoke: Palgrave Macmillan.

Hey, V. and Bradford, S. 2006 "Re-engineering motherhood? Sure Start in the community", Contemporary Issues in Early Childhood, 7(1): 53-67.

Hoggart, R. 2009. The Uses of Literacy: Aspects of Working-Class Life, London: Penguin. 
Kamp, A. and McSharry, M. 2018. "Conceiving a re/assemblage of teenage pregnancy and parenting” In Re/Assembling the Pregnant and Parenting Teenager: Narratives from the Field(s), edited by A, Kamp and M. McSharry, 1-26, Oxford: Peter Lang.

Kidger, J. 2004. 'Including young mothers: limitations to new labour's strategy for supporting teenage parents", Critical Social Policy, 24(3): 291-311.

Larkin, M., Watts, S. and Clifton, E. 2006. "Giving voice and making sense in interpretative phenomenological analysis", Qualitative Research in Psychology, 3(2): 102-120.

Levitas, R. 1998. The Inclusive Society? Social Exclusion and New Labour, London: Palgrave Macmillan.

O'Neill, O. 1996. "Introduction” In The Sources of Normativity, edited by C. Korsgaard, xixv, Oxford: Oxford University Press,

Phoenix, A. 1991. Young Mothers?, Cambridge: Polity Press.

Rawls, J. 1971. A Theory of Justice, Oxford: Oxford University Press.

Reay, D. and William, D. 1999. "'I'll be a nothing': structure, agency and the construction of identity through assessment”, British Educational Research Journal, 25(3): 343-354.

Rolfe, A. 2008. “'You've got to grow up when you've got a kid': Marginalised young women's account of motherhood", Journal of Community and Applied Social Psychology, 18(4): 299-314.

Rudoe, N. 2014. "Becoming a young mother: teenage pregnancy and parenting policy", Critical Social Policy, 34(3): 93-311.

Sayer, A. 2005. "Class, moral worth and recognition”, Sociology, 39(5): 947-963.

Skeggs, B. 1997. Formations of Class and Gender: Becoming Respectable, London: SAGE.

Skeggs, B. 2011. "Imagining personhood differently: person value and autonomist working class value practices", The Sociological Review, 59(3): 496-513.

Skeggs, B. and Loveday, V. 2012. "Struggles for value: value practices, injustice, judgement, affect and the idea of class", The British Journal of Sociology. 63(3): 472-490.

Smith, J. A., Flowers, P., and Larkin, M. 2009. Interpretative Phenomenological Analysis: Theory, Method and Research, London: SAGE.

Vincent, K. 2012. Schoolgirl Pregnancy, Motherhood and Education: Dealing with Difference, Stoke-on-Trent: Trentham Books.

Vincent, K. and Thomson, P. 2013. "Your age don't determine whether you're a good mum": reframing the discourse ascribed to teenage mothers, Social Alternative, 32(2): 6-12. 
Walkerdine, V., Lucey, H., and Melody, J. 2001. Growing up Girl: Psychosocial Explorations of Gender and Class, Basingstoke: Palgrave Macmillan.

Weis, L. 1995. "Identity formation and the processes of 'othering': unravelling sexual threads", Educational Foundations, 9(1): 17-33.

Williamson, H. 1997. "Status zero youth and the underclass" In Youth the 'Underclass' and 'Social Exclusion' edited by R. MacDonald, 70-82, London: Routledge,

Wilson, H., and Huntington, A. 2005. "Deviant (m)others: the construction of teenage motherhood in contemporary discourse", Journal of Social Policy, 35(1): 59-76.

Youdell, D. 2006. Impossible Bodies, Impossible Selves: Exclusions and Student Subjectivities, London: Springer.

Young, J. 1999. The Exclusive Society: Social Exclusion, Crime and Difference in Late Modernity, London: SAGE.

Zito, R.C. 2018. "Children as saviors? A propensity score analysis of the impact of teenage motherhood on personal transformation" Youth and Society, 50(8): 1100-1122. 